\title{
КЛИНИЧЕСКИЙ СЛУЧАЙ ГИПОПИТУИТАРИЗМА В СОЧЕТАНИИ С СИНДРОМОМ KAРTAГЕНЕРA
}

\author{
А.А. Биканова \\ Казанский государственный медицинский университет, Казань
}

Гипопитуитаризм - эндокринологическое заболевание, в результате которого происходит частичное или полное отсутствие секреции одного или более гормонов аденогипофзиза.

Синдром Картагенера - редкое наследственное аутосомно-рецессивное заболевание, причиной которого является утрата функции некоторых частей аксонемального центрального аппарата флагелл и цилий (чаще потеря функции динеиновых ручек), клинически характеризующийся транспозицией внутренних органов, аномалией мукоцилиарного клиренса, хроническим бронхитом и риносинуситом.

Частота встречаемости гипопитуитаризма 1:4000-10000, синдрома Картагенера 1:3000050000 детей.

ЦЕЛЬ: демонстрация клинического случая в виде редкого сочетания синдрома Картагенера и гипопитуитаризма.

Пациентка Г., 2015 г.р., поступила в плановом порядке в эндокринологическое отделение с жалобами на задержку физического (отставание в росте и в массе тела от сверстников) и психоэмоционального развития с рождения.

ИЗ АНАМНЕЗА: девочка родилась от 1 беременности, протекавшей на фоне анемии легкой степени тяжести, пневмонии (на сроке 5-6 мес) и хронической фетоплацентарной недостаточности; роды срочные, оперативные, 40,5 нед.

При рождении рост 51 см, вес 3030 грамм. При проведении КТ внутренних органов выявлена транспозиция органов грудной и брюшной полости.

У эндокринолога наблюдается с мая 2017 г., когда впервые на основании данных объективного осмотра (питание пониженное, телосложение астеническое, грубая задержка темпов моторного и нервно-психического развития) и лабораторных данных (снижение уровня Т4 свободного и ИФР-1) был выставлен диагноз: «Задержка физического и психического развития. Вторичный гипотиреоз? Соматотропная недостаточность?». Была назначена терапия л-тироксином 12,5 мкг 1 раз в сутки.

В октябре 2018г. консультирована генетиком. Status localis: Микросомия, тригоноцефалия, нависающий лоб, гипотелоризм, узкие носовые ходы, короткий фильтр, микростомия, дисплазия зубной эмали, «готическое нёбо», низкопосаженные ушные раковины. Диагноз: «Врождённые аномалии развития. Задержка психофизическогго развития. Синдром Картагенера. Вторичный гипотиреоз».

При кариотипировании: «Нормальный женский кариотип. 46, XX. Хромосомной патологии не выявлено».

В феврале 2019 г. обследована в эндокринологическом отделении. Проведены СТГ-стимуляционные пробы с клофелином (максимальный выброс соматотропина 0,2 нг/мл) и с инсулином (максимальный выброс гормона роста 1,27 нг/мл), по результатам которых сделано заключение: «Тотальный дефицит гормона роста». Назначен соматотропин в дозе 0,033 мг/кг ежедневно, подкожно в 20.00-22.00. Рост на момент старта заместительной терапии составлял 76 см, SDS - 5,5, вес 7,7 кг, ИМТ 13,3 кг/кв.м, SDS ИМТ - 2,1.

Объективно: рост 93 см (SDS роста - 3.10), вес 11.5 кг (за 11 мес. +2 кг); ИМТ 12.72 кг/кв.м.; SDS ИМТ - 3.11). На фоне

По результатам гормонального профиля: уровень Т4 свободного в целевом диапазоне (прием л-тироксина 37,5 мкг), уровень пролактина и кортизола в норме. Костный возраст соответствует 2 годам. На фоне терапии отмечался значимый прогресс в психомоторном развитии ребенка.

КЛИНИЧЕСКИЙ ДИАГНОЗ:

Основной: Гипопитуитаризм. Соматотропная недостаточность. Вторичный гипотиреоз.

Сопутствующий: Синдром Картагенера. Трихиаз. Аномалия развития наружного носа. Резидуальная энцефалопатия. Синдром мышечной гипотонии. Задержка психомоторного и речевого развития.

ВывоД: своевременная диагностика гипопитуитаризма позволяет своевременно начать и проводить эффективную терапию, благоприятно воздействующую на качество жизни пациента. 